\title{
Evaluation of Individual Growth Performance of Goat Kids by Using Multilevel Models
}

\author{
Suna Akkol (Corresponding author) \\ Van Yuzuncu Yil University, Faculty of Agriculture, \\ Department of Animal Science, Van/Turkey \\ Email: sgakkol@yyu.edu.tr \\ Ozdal Gokdal \\ Aydin Adnan Menderes University, Cine Vocational School, \\ Department of Plant and Animal Production, Cine, Aydin/Turkey \\ E-mail:ogokdal@yahoo.com \\ Okan Atay \\ Aydin Adnan Menderes University, Cine Vocational School, \\ Department of Plant and Animal Production, Cine, Aydin/Turkey \\ E-mail:okan_atay@yahoo.com
}

\begin{abstract}
The aim of this study was to evaluate the individual growth performances of hair goats and hybrids grown in extensive conditions performing two-level linear regression analysis for the period up to the sixth month from birth. Live weight records of 33 male and 57 female males were used in the study. -2LL, AIC and BIC statistics were used to find the covariance structure and model that best explain the change of the live weight occurring from birth to sixth month. According to the results, it was suitable two-level linear regression model which the random intercept and random slope with UN covariance structure for both male and female goat kids. According to this, birth weight, time and time-birth type interaction effect were found to be significant for males on the change in body weight, whereas birth weight, type of birth, time and time-birth interaction effect were significant for females $(\mathrm{P}<0.01)$. The change in growth performance from individual to individual was found to be significant for both genders $(\mathrm{P}<0.01)$.
\end{abstract}

Keywords: Hair goat, multilevel modeling, individual growth curve, covariance structure

DOI: $10.7176 / \mathrm{JSTR} / 5-3-12$

\section{Çok Düzeyli Modeller Kullanılarak Oğlaklarda Bireysel Büyüme- Gelişme Performansının Değerlendirilmesi*}

Özet

$\mathrm{Bu}$ çalışma, iki düzeyli doğrusal regresyon analizi kullanılarak ekstansif koşullarda yetiştirilen Kıl keçi ve melezlerinin doğumdan itibaren altıncı aya kadar olan dönem için bireysel büyüme performanslarının değerlendirilmesi amacıyla yapıldı. Çalışmada 33 baş erkek ve 57 baş dişi oğlağa ait canlı ağırlık kayıtları kullanıldı. Doğumdan altıncı aya kadar canlı ağırlıkta meydana gelen değişimi en iyi açıklayan kovaryas yapısı ve modeli bulmak için -2LL, AIC ve BIC istatistiklerinden yararlanıldı. Sonuçlara göre hem dişi hem erkek oğlaklar için UN kovaryans yapına sahip kesim noktası ve eğimin şansa bağlı olduğu iki düzeyli doğrusal regresyon modelinin uygun olduğu belirlendi. Buna göre, canlı ağırlıktaki değişim üzerine erkekler için doğum ağırlığı, zaman ve zaman-doğum tipi interaksiyon etkisi anlamlı bulunurken, dişiler için doğum ağırlığı, doğum tipi, zaman ve zaman-doğum tipi interaksiyon etkisi anlamlı bulundu $(\mathrm{P}<0.01)$. Her iki cinsiyet için büyüme performanslarının bireyden bireye değişimin anlamlı olduğu ortaya koyuldu $(\mathrm{P}<0.01)$.

Anahtar kelimeler: Kıl keçisi, çok düzeyli modelleme, bireysel büyüme eğrisi, kovaryans yapısı

*Bu çalışmanin bir kısmı "International Conference on Agriculture, Forest, Food Sciences and Technologies (ICAFOF 2017) " isimli kongrede poster bildiri olarak sunulmuştur. 


\section{GíRiş}

Türkiye'deki keçi varlığının büyük kısmını 10 milyon 419 bin baş ile Kıl keçileri oluşturmaktadır (TUIK, 2017). Daha çok orman içi ve kenarı köyler ile dağlık kesimlerde, çoğunlukla tarla veya bahçe tarımına uygun olmayan ve diğer hayvan türleri tarafından değerlendirilemeyen engebeli arazilerde yetiştiriciliği yoğunlaşmaktadır. Verim özellikleri genel olarak düşük olarak kabul edilirken, çoğu yörede işletme gelirleri içinde öncelikli olarak oğlak (et üretimi) gelirleri ilk sırada gelmektedir (Atay ve ark., 2011). Son yıllarda Kıl keçilerin süt ve oğlak verim özelliklerinin artırılmasına yönelik olarak özellikle Saanen ve Alpin irklarıyla çeşitli melezleme çalışmaları yapılmaktadır (Şengonca ve ark., 2003; Şimşek ve ark., 2007; Gökdal ve Atay, 2010; Gökdal ve ark., 2013; Erduran ve Dağ, 2016; Çelik ve Olfaz, 2018).

Türkiye'de keçilerden elde edilen et miktarı azımsanamayacak orandadır. 2017 yılında üretilen kırmızı etin \%3.33'ü keçiler tarafindan üretilmiştir (TUIK, 2017). Ancak keçilerin et üretim potansiyelinden yeterince yararlanılamadığı görülmektedir. Et üretiminde, sürü düzeyinde döl verimi ve oğlakların yaşama gücü ile oğlakların büyüme-gelişme özellikleri ön plana çıkmaktadır. Yörelere göre özgün koşullar dikkate alınarak oğlak eti miktar ve kalitesini artıracak yetiştirici organizasyonları ve ıslah planlamaları yapılmalıdır (Gökdal ve Atay, 2011). Bu bağlamda farklı koşullarda oğlakların büyüme ve gelişme özelliklerinin saptanması ve bu özellikler ait verilerin etkin bir şekilde değerlendirilmesi önem taşımaktadır.

Hayvancılık alanında büyüme performansları ile ilgili yapılan çalışmalarda veriler, her bir hayvandan belirli zaman aralıklarıyla alınan ölçümlerden oluşmaktadır. Tekrarlamalı ölçüm verileri olarak isimlendirilen bu tür veriler, doğal bir hiyerarşiye sahip olmaktadırlar. Zira her bir bireyden tekrarlamalı olarak alınan ölçümler, birey içi zaman şeklinde iki düzeyli bir hiyerarşik yapı sergilemektedir. Herhangi bir sınıflama veya hiyerarşiye sahip bu tip verilerin analizi için son yıllarda çok düzeyli (multilevel) regresyon modelleri kullanılmaya başlamıştır (Akkol ve ark., 2018; Ghaderi_Jzefrehei ve ark., 2018) Çok düzeyli modeller (Goldstein 1989, 2003; Snijders ve Bosker, 1999) literatürde aynı zamanda hiyerarşik modeller (Bryk ve Raudenbush 1986; Raudenbush ve Bryk 2002), şansa bağlı katsayılar modeli (Leeuw ve Kreft 1986) ve varyans unsurları modeli (Aitkin ve Longford, 1986) ismi ile de bilinen modellerdir. Çok düzeyli modelleme mantığında tekrarlamalı bir şekilde elde edilen veriler, iki düzeyli modeli ifade etmektedir (Singer, 1998; Hedeker, 2004; Hedeker ve Gibbons, 2006; Akkol ve ark., 2018). İki düzeyli bir modellemede, ilk olarak en üst düzeyden örnekler alınır. Daha sonra alınan bu örneklerin her biri için alt birimler örneklenir. Tekrarlamalı ölçüm çalışmalarında birey/hayvan en üst düzeyi ve her bir bireyden zamana bağlı olarak elde edilen tekrarlamalı ölçümler ise alt düzeyi gösterir. Dolayısıyla iki düzeyli bir modelde ikinci düzey birimleri bireyler/hayvanlar ve birinci düzey birimleri zamanı ifade etmektedir (Hox, 2010).

$\mathrm{Bu}$ çalışmada, iki düzeyli doğrusal regresyon analizi kullanılarak ekstansif koşullarda yetiştirilen Kıl keçi ve melezlerinin doğumdan itibaren altıncı aya kadar olan dönem için bireysel büyüme performanslarının değerlendirilmesi amaçlanmıştır.

\section{MATERYAL VE YÖNTEM}

\subsection{MATERYAL}

Bu çalışmanın materyalini, Aydın İli Çine İlçesi’nde Kavşit Köyü merkezli olarak 2003 yılından itibaren yürütülmekte olan "Kavşit Köyü ve Yöresi Keçicilik Projesi”" (Gökdal ve Atay, 2010) kapsamında iki farklı yetiştirici sürüsünden elde edilen Kıl keçisi ve melezi oğlaklar oluşturmuştur. Kavşit, Aydın İli Çine İlçesi'nden 10 km uzaklıkta olup orman kenarında yer almaktadır (37 $65^{\prime}$ kuzey enlemi ve $28^{\circ} 13^{\prime}$ doğu boylamı, rakım: 700 m). Çalışma materyali olan ve büyüme-gelişme performansları değerlendirilen 33 baş erkek ve 57 baş dişi olmak üzere toplamda 90 baş Saanen x Kıl (SK), Alpin x Kıl (AK) ve Kıl (K) keçisi oğlak, çalışma süresince ekstansif koşullarda yetiştirilmiş̧lerdir. Veriler, doğumdan itibaren ayda bir olmak üzere altıncı aya kadar olan canlı ağırlıkları içermektedir. Tekrarlamalı olarak elde edilen canlı ağırlıkların bağımlı değişken olarak yer aldığı modelde, doğum tipi (DT), ana yaşı (AY), genotip ve işletme bağımsız değişkenler olarak yer almıştır. Bu değişkenlerin tamamı zamana bağlı olarak değişmeyen değişkenlerdir ve iki düzeyli bir modelde, düzey iki değişkenleri olarak modele yazılmıştır.

Çalışmada istatistiksel analizler için SAS, V9.4 (SAS, 2018) kullanılmıştır.

\subsection{YÖNTEM:}

Çalışmada, sürüde senkronize aşımları takiben doğum döneminde oğlakların doğum kayıtları alınmıştır. Bir haftalık yaştan itibaren de oğlakların canlı ağırlıkları iki haftalık aralıklarla 50 gr hassasiyete sahip kantarla tartılarak saptanmıştır.

Çalışmada elde edilen verilerin değerlendirilmesinde kullanılan iki düzeyli modeller aşamalı olarak Model I, II ve III şeklinde verilmiştir. Modeller ve kullanılan eşitlikler sırasıyla (Singer, 1998; Raudenbush ve Bryk, 2002; Goldstein, 2003; Hox, 2010):

Model I: Kesim noktasının şansa bağlı olduğu iki düzeyli doğrusal büyüme modeli: Bu modelde kesim noktası şansa bağlıdır ve modelde sadece zaman etkisi incelenmektedir. 
Düzey 1: $Y_{t i}=\pi_{0 i}+\pi_{1 i} T_{t i}+e_{t i}$

Düzey 2: $\begin{aligned} & \pi_{0 i}=\beta_{00}+u_{0 i} \\ & \pi_{1 i}=\beta_{10}\end{aligned}$

Düzey 2'de verilen detaylar düzey 1'de yerine yazılarak aşağıdaki eşitlik elde edilir.

$Y_{t i}=\beta_{00}+\beta_{10} T_{t i}+u_{0 i}+e_{t i}$

Burada $Y_{t i}$ i’ninci bireyin t’ninci zamandaki canlı ağırlığını gösterir. $\beta_{00}$, kuzuların ortalama doğum ağırlı̆̆ını; $T_{t i}$ i'ninci bireyin t'ninci ölçüm zamanını, $\beta_{10}$ eğimi, bir diğer ifade ile zamana bağlı olarak canlı ağırlıkta meydana gelen ortalama değişim miktarını, $u_{0 i}$ doğum ağırlığı etrafindaki ortalama sapmayı yani düzey iki hata miktarını ve $e_{t i}$ birinci düzeydeki hata miktarın ifade eder. Düzey iki hata miktarı olarak bilinen $u_{0 i}$ için $u_{0 i} \sim$ $N\left(0, \sigma_{u_{0}}^{2}\right)$ varsayımı ve düzey bir hatası için $e_{t i} \sim N\left(0, \sigma_{e}^{2}\right)$ varsayımı yapılır.

Model II: Kesim noktasının şansa bağlı olduğu ve birey düzeyinde bir diğer ifade ile düzey 2'de bağımsız değişkenlerin yer aldığı iki düzeyli doğrusal büyüme modeli.

Düzey 1: $Y_{t i}=\pi_{0 i}+\pi_{1 i} T_{t i}+e_{t i}$

Düzey 2: $\pi_{0 i}=\beta_{00}+\beta_{01} W_{i}+u_{0 i}$

Düzey 2'nin düzey 1'de yerine koyulması ile 2 numaralı eşitlik aşağıdaki gibi olur.

$Y_{t i}=\beta_{00}+\beta_{10} T_{t i}+\beta_{01} W_{i}+u_{0 i}+e_{t i}$

Yukarıda verilen 1 numaralı eşitlikteki bilgilere ek olarak $W_{i}$ zamana bağlı olarak değişmeyen değişkenleri; $\beta_{01}$ bu değişkenlerdeki birim değişime karşılık canlı ağıllıkta meydana gelen ortalama değişim miktarını göstermektedir. Şansa bağlı etkiler Model I'de açıklandığı gibidir.

Model III: Bu model, düzey 2 eşitliğinde hem kesim noktasının hem de eğimin şansa bağlı olduğu iki düzeyli modeli ifade etmektedir. Buna göre düzey 1 ve 2 eşitlikleri aşağıdaki gibi yazılır ve 3 numaralı eşitlikte birlikte verilir.

Düzey 1: $Y_{t i}=\pi_{0 i}+\pi_{1 i} T_{t i}+e_{t i}$

Düzey 2: $\begin{aligned} & \pi_{0 i}=\beta_{00}+\beta_{01} W_{i}+u_{0 i} \\ & \pi_{1 i}=\beta_{10}+\beta_{11} W_{i}+u_{1 i}\end{aligned}$

$Y_{t i}=\beta_{00}+\beta_{10} T_{t i}+\beta_{01} W_{i}+\beta_{11} T_{t i} W_{i}+u_{1 i} T_{t i}+u_{0 i}+e_{t i}$

Yukarıda verilen eşitlikte yer alan terimlerden $\beta_{11}$ ve $u_{1 i}$ dışındaki terimler daha önce açıklandığı gibidir. Eşitlik 3 ’te $\beta_{11}$ zaman ile zamana bağlı değişmeyen değişkenlerin birlikte değişimini (interaksiyon etkiyi) ve $u_{1 i}$ Düzey iki hata miktarı olup zamana bağlı olarak canlı ağırlıkta meydana gelen ortalama değiş̧imin şansa bağlı değişim miktarını gösterir. Düzey iki hata terimleri için $\mathbf{u}_{i}=\left[u_{0 i}, u_{1 i}\right]^{T} \sim N\left(\mathbf{0}, \boldsymbol{\Omega}_{u}\right)$ varsayımı yapılır.

Yukarıda verilen 1, 2 ve 3 numaralı eşitlikler hem sabit hem de şansa bağlı terimleri bir arada bulundurmaktadır. Yukarıda açıklanan tüm modeller, matris formunda aşağıdaki gibi gösterilmektedir (Golstein ve ark., 2002; Golstein, 2003):

$Y=X \beta+E$

Modelin şansa bağlı kısmında düzey 1 ve düzey 2 için eşitlik aşağıdaki gibi olur.

$Y=X \beta+Z^{(2)} u+Z^{(1)} e$

Genel olarak iki düzeyli bir model için hata matrisi, $V_{2}=V_{2(2)}+V_{2(1)}$ şeklinde ifade edilir. Buna göre

$V_{2(1)}=\operatorname{Var}\left(e_{i j}\right)=\sigma_{e}^{2}=z_{t j}^{(1)} \Omega_{e} z_{t j}^{(1)}, \Omega_{e}=\sigma_{e}^{2}$ 


$$
V_{2(2)_{j}}=z_{j}^{(2)} \Omega_{u}^{\prime} z_{j}^{(2)}, \boldsymbol{\Omega}_{u}=\left(\begin{array}{cc}
\sigma_{u_{0}}^{2} & \sigma_{u_{01}} \\
\sigma_{u_{01}} & \sigma_{u_{1}}^{2}
\end{array}\right)
$$

olmaktadır. Çok düzeyli modelleme karışı modeller içinde yer almakta ve tahmin denklemleri yapısal olmayan (unstructured) kovaryans yapısı kullanılarak elde edilmektedir. Ancak yine de çeşitli kovaryans yapılarının kullanımına izin veren bir regresyon analiz tekniğidir.

Tahmin Yöntemleri: İteratif genelleştirilmiş en küçük kareler, (IGLS/ML: Genelleştirilmiş En Küçük Kareler (GLS) tahminine dayanan iteratif bir yöntemdir (Goldstein, 2003). Yukarıda 4 numaralı eşitlik ile verilen $E=e^{*}=u_{j}+e_{i j}$ yazılır ve $e^{*}$ 'nin ortalaması sıfır ve kovaryans matrisi $V$ tanımlaması yapılsın. Sabit etkiler için GLS eşitliği,

$\hat{\beta}=\left(X^{\prime} V^{-1} X\right)^{-1} X^{\prime} V^{-1} Y$

olur. $\beta$ 'lar bulunduktan sonra $\tilde{Y}=Y-X \beta=e^{*}$ ve $Y^{*}=\tilde{Y} \tilde{Y}^{\prime}$ çarpımlar vektörü olursa, bunun beklenen değeri basit bir şekilde $V$ olur.

$E\left(Y^{*}\right)=V$

$Y^{* *}=v e c\left(Y^{*}\right)$ tanımlaması yapılarak şansa bağlı etkiler için tahmin eşitliği,

$E\left(Y^{* *}\right)=Z^{*} \theta$

Yazılır. Burada $Z^{*}$ şansa bağlı etkilere ilişkin katsayı matrisidir ve $\theta$ şansa bağlı etkileri gösterir. $\theta$ için tahmin denklemi aşağıdaki gibi ifade edilir.

$\hat{\theta}=\left(Z^{*} V^{*-1} Z^{*}\right)^{-1} Z^{*^{\prime}} V^{*-1} Y^{* *}$

Burada $V^{*}=V \otimes V$ ve $\otimes$ kronecer çarpım işlemini gösterir. Tahminler için yakınsama gerçekleştiği zaman modelde yer alan sabit ve şansa bağlı etkiler için tahmin yapılmış olur. Ancak bu yöntem ile küçük örnek setlerinde özellikle şansa bağlı etkiler için yapılan tahminlerin, olması gerekenden daha kü̧̈ük bir değer alması söz konusu olabildiği için Goldstein (1989) tarafından, $\hat{\beta}$ 'nın örnekleme varyansının hesaba katıldığı bir düzeltme yapmıştır.

$$
E\left(Y^{*}\right)=V-X \operatorname{cov}(\hat{\beta}) X^{\prime}=V-X\left(X^{\prime} V^{-1} X\right)^{-1} X^{\prime}
$$

Bu düzeltme ile elde edilen yöntem, kısıtlanmış iteratif genelleştirilmiş en küçük kareler (RIGLS) yöntemi olarak bilinmektedir. RIGLS yönteminde hatalar için $\tilde{Y}=Y-X \beta=e^{*}$ yerine $\tilde{Y}^{*}=Y-X \hat{\beta}$ ve $\hat{Y}^{*}=\tilde{Y}^{*}\left(\tilde{Y}^{*}\right)^{\prime}$ tanımlaması yapıldıktan sonar, $\hat{Y}^{*}, 9$ numaralı eşitlikte kullanılarak sapma giderilmiş olur (Golstein, 2003; Browne ve Draper, 2006).

Model Karşılaştırma ve Seçim Ölçütü: Çalışmada canlı ağırlıktaki değişimi en iyi açıklayan modeli bulmak amacıyla kullanılan uyum ölçütleri $-211(-2 * \log$ olabilirlik) değeri, Akaike bilgi ölçütü (Akaike Information Criteria: AIC) (Akaike, 1974) ve Schwarz Bayesian bilgi ölçütü (Schwarz Bayesian Information Criterion: SBC) (Schwards, 1978) kullanıld1.

$$
\begin{aligned}
& A I C=-2 l l+2 p \\
& B I C=-2 l l+p \ln (n)
\end{aligned}
$$

burada $L L$ log-olabilirlik değeri, $p$ modelde yer alan açıklayıcı değişken sayısı ve $\mathrm{n}$ örnek büyüklüğünü göstermektedir.

\section{BULGULAR VE TARTIŞMA}

Dişi ve erkek oğlakların doğumdan (Zaman 0) altıncı aya kadar (Zaman 6) olan canı ağırlıklarına ilişkin temel istatistikler Tablo 1'de verilmiştir. Çalışmada kullanılan veri setindeki oğlakların \%37'si erkek ve \%63'ü dişi olup, toplam 90 oğlak cinsiyetlerine göre ayrı başlıklar altında incelenmiştir. Tablo 1'de canlı ağırlıkların doğumdan itibaren artışı gözlenirken aynı zamanda varyansın da özellikle her iki cinsiyet için beşinci aya kadar arttığı

91 | P a g e 
International Journal of Scientific and Technological Research

ISSN 2422-8702 (Online), DOI: 10.7176/JSTR/5-3-12

Vol.5, No.3, 2019

görülmektedir. Altıncı aya gelindiğinde ağırlık artışına rağmen her iki cinsiyet için de varyans miktarında azalma dikkat çekici olmuştur.

Tablo 1. Cinsiyetlere göre doğumdan (Zaman 0) altıncı aya (Zaman 6) kadar olan canlı ağırlıklara ilişkin temel istatistikler

\begin{tabular}{rrrrrrrrr}
\hline & \multicolumn{3}{c}{ Erkek } & \multicolumn{3}{c}{ Dişi } \\
\hline Canlı ağırlık & $\mathrm{N}$ & Min & Max & \multicolumn{1}{c}{$\bar{X} \pm S$} & $\mathrm{~N}$ & Min & Max & \multicolumn{1}{c}{ $\pm S$} \\
\hline Zaman 0 & 33 & 2.40 & 4.60 & $3.15 \pm 0.67$ & 57 & 1.70 & 4.20 & $2.94 \pm 0.54$ \\
Zaman 1 & 33 & 4.56 & 10.39 & $7.53 \pm 1.74$ & 57 & 3.55 & 9.63 & $6.75 \pm 1.49$ \\
Zaman 2 & 33 & 6.17 & 17.26 & $11.91 \pm 3.37$ & 57 & 5.06 & 15.24 & $10.26 \pm 2.52$ \\
Zaman 3 & 33 & 6.86 & 23.10 & $16.15 \pm 5.05$ & 57 & 6.61 & 20.62 & $14.53 \pm 3.77$ \\
Zaman 4 & 33 & 7.30 & 29.57 & $20.18 \pm 5.94$ & 57 & 8.50 & 26.80 & $17.19 \pm 4.92$ \\
Zaman 5 & 32 & 10.15 & 34.96 & $24.20 \pm 5.95$ & 57 & 11.56 & 32.74 & $21.18 \pm 5.36$ \\
Zaman 6 & 30 & 14.28 & 36.74 & $27.19 \pm 5.66$ & 56 & 15.60 & 35.92 & $24.16 \pm 5.22$ \\
\hline
\end{tabular}

Her iki cinsiyete ait doğum ve sonraki altı ay içinde hesaplanan varyanslara ait grafik Şekil 1 'de sunulmuştur. Şekil 1'de de görüldüğü gibi erkek oğlaklar arasındaki varyasyon dişilerden tüm büyüme-gelişme dönemi boyunca yüksek olmasına rağmen varyanstaki büyüme dişi oğlaklardan daha hızlı şekilde ve daha erken durmuştur.

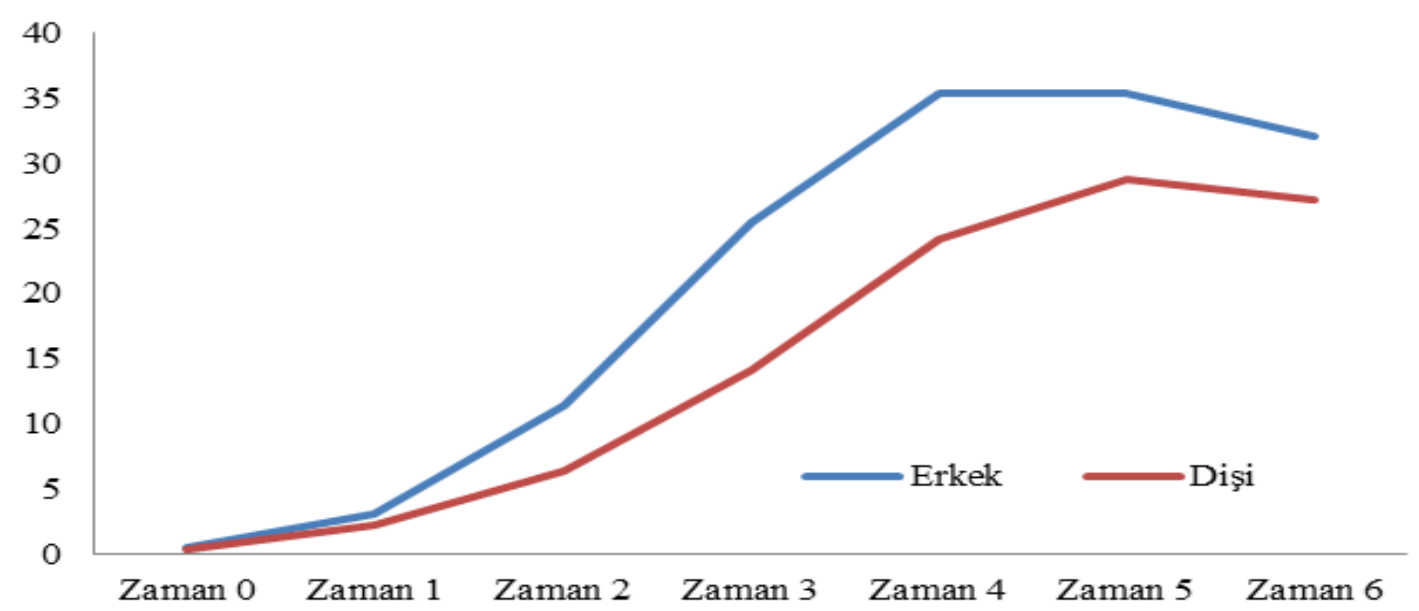

Şekil 1. Erkek ve dişi oğlaklar için doğum ve sonraki altı aya ait varyans miktarları

Etkisi incelenen doğum tipi, ana yaşı, genotip ve işletme değişkenleri için frekanslar Tablo 2'de verilmiştir. Tablo 2 incelendiğinde, ikiz erkeklerin tek doğan erkeklerden ve tek doğan dişilerin ikiz dişilerden sayısal olarak daha fazla olduğu görülmektedir. Aynı zamanda Tablo 2'de özetlenen bilgilere göre her iki cinsiyet için de dört yaşlı analar 2, 3, 5 ve 6 yaşlı analardan, SK oğlakları, AK ve K oğlaklarından, birinci işletmede erkek oğlaklar dişilerden ve ikinci işletmede dişi oğlaklar erkeklerden sayısal olarak daha fazla olmuştur. 
Tablo 2. Etkisi incelenen kesikli değişkenlere ilişkin frekanslar

\begin{tabular}{|c|c|c|c|}
\hline & & Erkek & Dişi \\
\hline \multicolumn{2}{|c|}{ Değişken } & Frekans $(\%)$ & Frekans (\%) \\
\hline \multirow[t]{2}{*}{ Doğum tipi } & Tek (1) & 45.45 & 50.88 \\
\hline & İkiz (2) & 54.55 & 49.12 \\
\hline \multirow[t]{5}{*}{ Ana yaşı } & 2 & 3.03 & 12.28 \\
\hline & 3 & 21.21 & 24.56 \\
\hline & 4 & 48.48 & 38.60 \\
\hline & 5 & 18.18 & 10.53 \\
\hline & 6 & 9.09 & 14.04 \\
\hline \multirow[t]{3}{*}{ Genotip } & Saanen x K1l (SK) keçisi & 51.52 & 45.61 \\
\hline & Alpin x Kıl (AK) keçisi & 24.24 & 33.33 \\
\hline & K1l (K) keçisi & 24.24 & 21.05 \\
\hline \multirow[t]{2}{*}{ İşletme } & 1 & 60.61 & 42.11 \\
\hline & 2 & 39.39 & 57.89 \\
\hline
\end{tabular}

Çok düzeyli regresyon analizi, çeşitli kovaryans yapılarının uyumunun test edilmesine imkan sağlayan bir analiz tekniği olduğu için, tekrarlamalı ölçümlerin analiz edildiği bu çalışmada çeşitli kovaryans yapıları (CS, UN, AR(1), ANTE (1),Toepliz) kullanılmıştır. Model I, II ve III için analizler yapıldıktan sonra -21l, AIC ve BIC değerleri kullanılarak yapısal olmayan kovaryans (UN) yapısının canlı ağırlıktaki değişimi en iyi açıklayan kovaryans yapısı olduğu belirlenmiştir. Bu sonuç, Akkol ve ark.'nın (2018) çalışması ile uyumlu ancak Wang ve Goonewardene'den (2004) farklı olmuştur. Akkol ve ark. (2018), kuzuların büyüme performansları üzerine yaptıkları çalışmada, UN kovaryans yapısı ile elde edilen sonuçların diğer kovaryans yapılarından (CS, UN, AR(1), Toepliz) daha iyi olduğunu ifade etmişlerdir. Ancak Wang ve Goonewardene'nın (2004) çalışmasında veriye uyum, en iyi ANTE (1) kovaryans yapısı kullanılarak sağlanmıştır.

Model I, II ve III için UN kovaryans yapısı kullanılarak iki düzeyli doğrusal regresyon analizinden elde edilen uyum ölçütleri, modellere ilişkin parametre sayıları ve $\chi^{2}$ test istatistiği sonuçları Tablo 3 'te verilmiştir.

Tablo 3. Erkek ve dişi oğlaklar için çalışmada kullanılan modellerden elde edilen uyum ölçütleri

\begin{tabular}{lrrrrrr}
\hline & \multicolumn{3}{c}{ Erkek } & & \multicolumn{2}{c}{ Dişi } \\
\hline Uyum Ölçütleri & \multicolumn{1}{c}{ Model I } & \multicolumn{1}{c}{ Model II } & Model III & Model I & Model II & Model III \\
\hline -2ll & 1154.8 & 1061.4 & 951.9 & 1908.1 & 1804.8 & 1418.8 \\
AIC & 1158.8 & 1065.4 & 959.9 & 1912.1 & 1808.8 & 1426.8 \\
BIC & 1161.8 & 1068.4 & 965.9 & 1916.2 & 1812.8 & 1434.9 \\
Parametre sayısı & 4 & 9 & 11 & 4 & -103.3 & 389.0 \\
Olabilirlik oran testi & - & 93.4 & 109.5 & - & 5 & 2 \\
Serbestlik derecesi & - & 5 & 2 & & $* *$ & $* *$ \\
$\chi^{2}$ & & $* *$ & $* *$ & & & \\
\hline
\end{tabular}

Tablo 3'te verilen -21l, AIC ve BIC değerleri incelendiğinde hem erkek oğlaklar hem dişi oğlaklar için Model III'ün en küçük değerlere sahip regresyon modeli olduğu görülmektedir. Bu değerler erkekler için sirasıyla 951.9, 959.9 ve 965.9 ve dişiler sırasıyla $1418.8,1426.8$ ve 1434.9 olmuştur. Canlı ağırlıktaki değişimi yansıtacak en iyi modeli belirleyebilmek, bir diğer ifade ile en iyi modeli bulabilmek için $\left(-2 l l_{\text {Indirgenmiş_Model }}\right)-\left(-2 l l_{\text {Geçerli_Model }}\right)$ eşitliği kullanılarak olabilirlik oran testi (LRT) yapılmış ve sonuçlar Tablo 3’te verilmiştir. Buna göre erkek oğlaklar için Model II Model I'den daha iyi $\left(\chi_{5}^{2}=93.4, \mathrm{P}<0.01\right)$ ve Model III Model II'den daha iyi $\left(\chi_{2}^{2}=109.5\right.$, $\mathrm{P}<0.01)$ bulunmuştur. Dişi oğlaklar için Tablo 3'te verilen LRT sonucuna göre, Model II'nin Model I'den $\left(\chi_{5}^{2}=\right.$ 103.3, $\mathrm{P}<0.01)$ ve Model III'ün Model II'den daha iyi $\left(\chi_{2}^{2}=389.0, \mathrm{P}<0.01\right)$ olduğu tespit edilmiştir. Uyum 
kriterleri ve LRT sonuçlarına dayanarak, Model III'ün hem erkek hem dişi oğlaklar için en iyi model olduğu ortaya koyulmuştur.

Erkek ve dişi oğlaklar için çok düzeyli regresyon analiz tekniği kullanılarak elde edilen sonuçlar, Tablo 4'te verilmiştir. Bu sonuçlar, çalışmada kullanılan modellerde bulunan sabit ve şansa bağlı etkiler için tahmin ve standart hata değerlerini içermektedir.

Tablo 4. İki düzeyli modelleme ile elde edilen sabit ve şansa bağlı etkilere ait tahmin ve standart hatalar

\begin{tabular}{|c|c|c|c|c|c|c|}
\hline \multirow[b]{3}{*}{ Sabit Etkiler } & \multicolumn{3}{|c|}{ Erkek } & \multicolumn{3}{|c|}{ Dişi } \\
\hline & Model I & Model II & Model III & Model I & Model II & Model III \\
\hline & $\operatorname{Tahmin} \pm \mathrm{SH}$ & $\operatorname{Tahmin} \pm \mathrm{SH}$ & $\operatorname{Tahmin} \pm \mathrm{SH}$ & $\operatorname{Tahmin} \pm \mathrm{SH}$ & $\operatorname{Tahmin} \pm \mathrm{SH}$ & $\operatorname{Tahmin} \pm \mathrm{SH}$ \\
\hline Sabit & $3.52 \pm 0.71^{* *}$ & $0.20 \pm 1.30$ & $2.30 \pm 0.75^{* *}$ & $3.04 \pm 0.46^{* *}$ & $1.66 \pm 0.92$ & $2.42 \pm 0.35^{* *}$ \\
\hline Zaman & $4.09 \pm 0.08^{* *}$ & $3.68 \pm 0.11^{* *}$ & $3.72 \pm 0.21^{* *}$ & $3.56 \pm 0.05^{* *}$ & $3.22 \pm 0.08^{* * *}$ & $3.22 \pm 0.17^{* * *}$ \\
\hline \multicolumn{7}{|l|}{ DT } \\
\hline Tek & & $-1.48 \pm 0.96$ & $0.98 \pm 0.50$ & & $0.88 \pm 0.71$ & $1.07 \pm 0.25^{* *}$ \\
\hline İkiz & & - & - & & - & - \\
\hline \multicolumn{7}{|l|}{ Zaman*DT } \\
\hline Tek & & $0.91 \pm 0.16^{* *}$ & $0.89 \pm 0.31^{* *}$ & & $0.65 \pm 0.10^{* *}$ & $0.66 \pm 0.23^{* *}$ \\
\hline İkiz & & - & - & & - & - \\
\hline \multicolumn{7}{|l|}{ Ana yaş1 } \\
\hline 2 & & $5.15 \pm 2.49^{*}$ & $0.55 \pm 1.52$ & & $-0.82 \pm 1.18$ & $-0.36 \pm 0.46$ \\
\hline 3 & & $-1.21 \pm 1.54$ & $-0.57 \pm 0.91$ & & $-1.22 \pm 1.15$ & $-0.58 \pm 0.45$ \\
\hline 4 & & $-0.82 \pm 1.40$ & $-0.29 \pm 0.83$ & & $-1.62 \pm 1.01$ & $-0.67 \pm 0.40$ \\
\hline 5 & & $-0.81 \pm 1.76$ & $0.002 \pm 1.04$ & & $-0.39 \pm 1.22$ & $-0.61 \pm 0.48$ \\
\hline 6 & & - & - & & - & - \\
\hline \multicolumn{7}{|l|}{ Genotip } \\
\hline SK & & $-0.34 \pm 1.03$ & $0.50 \pm 0.61$ & & $0.39 \pm 1.09$ & $0.52 \pm 0.43$ \\
\hline $\mathrm{AK}$ & & $3.93 \pm 1.26^{* *}$ & $0.76 \pm 0.75$ & & $-0.23 \pm 1.11$ & $0.36 \pm 0.44$ \\
\hline $\mathrm{K}$ & & - & - & & - & - \\
\hline \multicolumn{7}{|l|}{ İşletme } \\
\hline 1 & & $6.36 \pm 1.06^{* *}$ & $0.89 \pm 0.63$ & & $4.47 \pm 0.70^{* *}$ & $0.46 \pm 0.28$ \\
\hline 2 & & - & - & & - & - \\
\hline \multicolumn{7}{|c|}{ Şansa bağlı etkiler } \\
\hline$\sigma_{u_{0}}^{2}$ & $13.76 \pm 3.67^{* *}$ & $3.23 \pm 1.16^{* *}$ & $0.27 \pm 0.45$ & $9.92 \pm 2.01^{* *}$ & $3.65 \pm 0.87^{* *}$ & $0.14 \pm 0.140$ \\
\hline$\sigma_{u_{01}}$ & & & $0.43 \pm 0.36$ & & & $0.13 \pm 0.138$ \\
\hline$\sigma_{u_{1}}^{2}$ & & & $0.67 \pm 0.19^{* *}$ & & & $0.71 \pm 0.143^{* *}$ \\
\hline$\sigma_{e}^{2}$ & $6.34 \pm 0.65^{* *}$ & $5.44 \pm 0.56^{* *}$ & $2.50 \pm 0.28^{* *}$ & $4.75 \pm 0.36^{* *}$ & $4.28 \pm 0.33^{* *}$ & $1.11 \pm 0.09^{* *}$ \\
\hline
\end{tabular}

Tablo 4'te yer alan hem erkek hem dişi oğlaklar için kullanılan tüm çok düzeyli model eşitlikleri doğrusal olup Model I ve II sadece kesim noktasının, Model III ise hem kesim noktasının hem de eğimin şansa bağlı olarak değişim gösterdiği iki düzeyli regresyon modelini göstermektedir. Tabloda sabit, bir diğer ifade ile kesim noktası, zamanın sıfır olduğu noktada kuzuların canlı ağırlığına karşılık geldiği için kuzuların doğum ağırlığını ifade etmektedir. Her iki cinsiyet için modellerin tamamında yer alan sabit etkilerden kuzuların doğum ağırlı̆̆ ve zamanın etkisi anlamlı olduğu dikkat çekmektedir (dişi ve erkek oğlaklar için sırasıyla $\mathrm{P}<0.01, \mathrm{P}<0.01$ ). Model I 
başlangıç modeli olup açıklayıcı değişkenlerin yer almadığı bu modeldeki şansa bağlı etkiler, her iki cinsiyet için anlamlı bulunmuştur (düzey iki için $\mathrm{P}<0.01$ ve düzey bir için $\mathrm{P}<0.01$ ).

Model II eşitliğinde, incelenen tüm açıklayıcı değişkenler yer almış olup, bu model sınıf içi korelasyon (ICC) miktarının belirlenmesi için kullanılmıştır. Bu değer, $I C C=\sigma_{u 0}^{2} /\left(\sigma_{u 0}^{2} \sigma_{e}^{2}\right)$ (Raudenbush ve Bryk; 2002; Golstein, 2003) eşitliği kullanılarak her iki cinsiyet için ayrı ayrı değerlendirilmiştir. Erkekler için hesaplanan sınıf içi korelasyon $(I C C=3.23 /(3.23+5.44)=0.37) \quad I C C=\% 37$ olup, bu değer canlı ağırlıktaki değişimin \%37’lik kısmının oğlaklar arası farklılıktan ileri geldiğini göstermektedir. Dişiler için sınıf içi korelasyon ( $I C C=3.65 /(3.65+4.28)=0.54)$ değeri $\mathrm{ICC}=\% 54$ bulunmuştur. Bulunan bu sinıf içi korelasyon değeri, canlı ağırlıktaki değişimin \%54'lük kısmının oğlaklar arası farklıııktan ileri geldiğini ortaya koymaktadır. Tekrarlamalı veri üzerinde çalışan Shek ve Ma (2011) ICC değerini 0.67, Kwok ve ark. (2008) ise 0.49 olarak elde etmişlerdir. Buna göre erkekler için elde edilen ICC, Shek ve Ma (2011) ve Kwok ve ark.'nın (2008) elde ettiği ICC değerinden küçük olmuştur. Dişiler için bu çalışmadan elde edilen ICC değeri ise Shek ve Ma'nın (2011) elde ettiğinden büyük, ancak Kwok ve ark.'nın (2008) elde ettiği değerden küçük olmuştur. Her ne kadar Snijders ve Bosker (1999), kesitsel tasarımlarda (cross-sectional) ICC değerinin 0.05 ile 0.20 arasında olduğunu bildirmiş olsa da Kwok ve ark. (2008), zaman içinde aynı bireylerden tekrarlamalı olarak alınan ölçümlerin analizinde bu değerin daha büyük çıkmasının mümkün olduğunu bildirmişlerdir.

Model III, hem dişi hem erkek oğlakların büyüme ve gelişme performanslarındaki değişimi en iyi açıklayan şansa bağlı sabit ve eğime sahip model olmuştur (Tablo 3). Tablo 4'te, erkekler için Model III kullanılarak yapılan analiz sonuçları; doğum tipi, ana yaşı, genotip ve işletme faktörlerinin canlı ağırlıktaki değişimi açıklamada önemli bulunmadığını ortaya koymuştur. Doğum ağırlı̆̆ $(P<0.01)$, zaman $(\mathrm{P}<0.01)$, doğum ağırlığı ve zaman interaksiyon etkisi $(\mathrm{P}<0.01)$ anlamlı bulunmuştur. Buna göre erkek oğlakların doğum ağırlıklarının canlı ağırlık kazancı üzerine önemli bir etkiye sahip olduğu ortaya koyulmuştur $(2.30 \pm 0.75, \mathrm{P}<0.01)$. Zamandaki birim değişimle birlikte canlı ağırlıkta $3.72 \mathrm{~kg}$ artış meydana gelmiştir. Diğer bir ifade ile çalışmadaki erkek oğlakların canlı ağırlıkları doğumdan itibaren altıncı aya kadar olan süre içinde aylık olarak ortalama $3.72 \mathrm{~kg}$ artmıştır. Zaman ve doğum tipinin interaksiyon etkisinin anlamlı çıkmış olması, zamanın ilerlemesi ile birlikte tek doğan keçilerin ikiz keçilerden ortalama $0.89 \mathrm{~kg}$ daha fazla canlı ağırlık kazandığını ortaya koymaktadır. Buna göre, her ne kadar doğum tipi canlı ağırlık kazancı bakımından anlamlı bir etkiye sahip olmasa da zamanla içinde tek doğan oğlaklar ikiz oğlaklardan daha fazla canlı ağırlık kazancına sahip olmuştur. Şansa bağlı etkiler bakımından Model III’te erkeklerin ortalama doğum ağırlığı şansa bağlı değişim göstermesine rağmen bu değişim anlamlı bulunmamıştır ( $\sigma_{u_{0}}^{2}=0.27 \pm 0.45$ ). Tablo 4 'te Model III için verilen şansa bağlı etkilerden düzey ikiye ilişkin hata miktarının ( $\left.\sigma_{u_{1}}^{2}=0.67 \pm 0.19\right)$ önemli çıktığı görülmektedir $(\mathrm{P}<0.01)$. Dolayısıyla erkek oğlakların zaman içinde ortalama canlı ağırlık kazançlarının 3.72 kg olup her bir oğlağın canlı ağırlık kazançları birbirlerinden anlamlı ölçüde farklı bunmuştur. Sadece kesim noktasının şansa bağlı olduğu model ve hem kesim noktasının hem de eğimin şansa bağlı olduğu model için bireysel büyüme eğrileri Şekil 2'de verilmiştir.

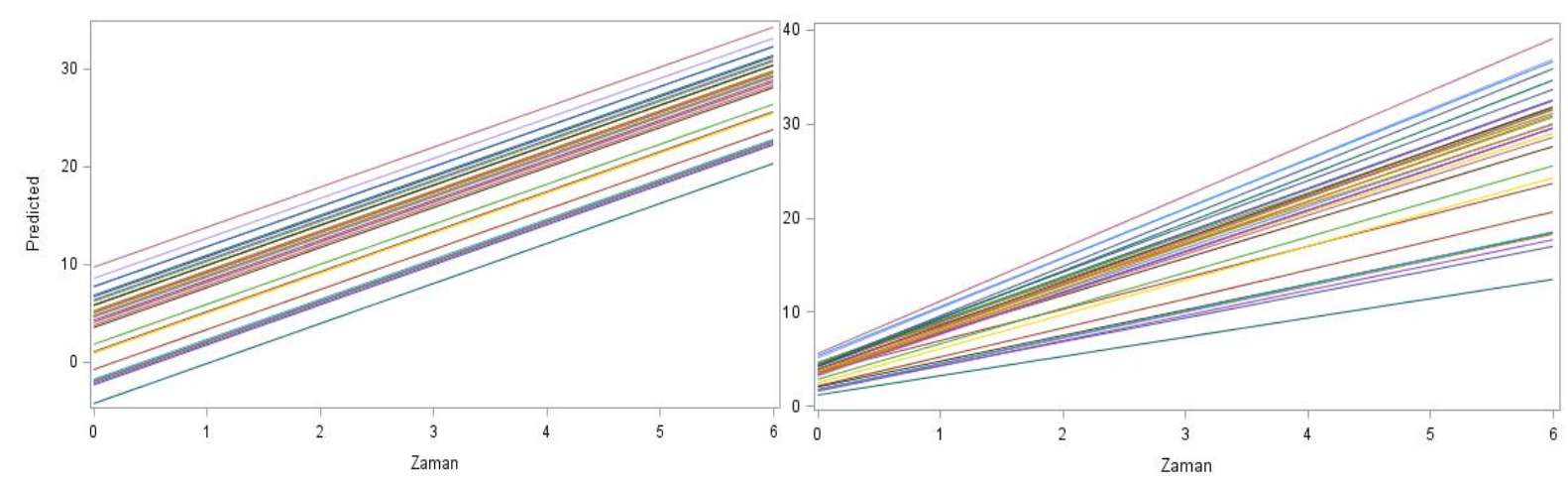

Şekil 2. Erkek oğlaklar için kesim noktasının (sol) ve hem kesim noktasının hem de eğimin şansa bağlı olduğu (sağ) iki düzeyli modeller ile elde edilen bireysel büyüme eğrisi

Dişi oğlaklar için Model III incelendiğinde ana yaşlarının, genotipin ve işletmelerin önemli bir etkiye sahip olmadığı görülmektedir (Tablo 4). Dişi keçiler için canlı ağırlık üzerine doğum ağırlığının, zamanın, doğum tipinin ve zaman doğum tipi interaksiyon etkisinin anlamlı olduğu $(\mathrm{P}<0.01)$ ortaya koyulmuştur. Dişi oğlakların aylık ortalama canlı ağırlık kazançlarının $3.22 \mathrm{~kg}$ olduğu; tek dişilerin ikizlere göre ortalama olarak $1.07 \mathrm{~kg}$ daha fazla ağırlığa sahip olduğu ve zaman ilerledikçe tek doğan oğlakların ikizlerden daha çok (ortalama $0.66 \mathrm{~kg}$ daha fazla) 
ağırlığa sahip olduğu tespit edilmiştir. Dişiler için Model III'de yer alan şansa bağlı etkiler incelendiğinde, düzey iki hatalarından $\sigma_{u_{1}}^{2}$ 'nin önemli çıktığı görülmektedir $(\mathrm{P}<0.01)$. Buna göre dişi oğlakların aylık ortalama canlı ağırlık kazançları 3.22 kg olup her bir oğlağın bireysel ağırlık kazançları birbirlerinden anlamlı ölçüde farklı olduğu sonucuna varılmıştır. $\sigma_{u_{0}}^{2}$ ve $\sigma_{u_{01}}$ ise anlamlı bulunmamıştır. Dişiler için sadece kesim noktasının şansa bağlı olduğu model ve hem kesim noktasının hem de eğimin şansa bağlı olduğu modeller için bireysel büyüme eğrileri Şekil 3 'te sunulmuştur.

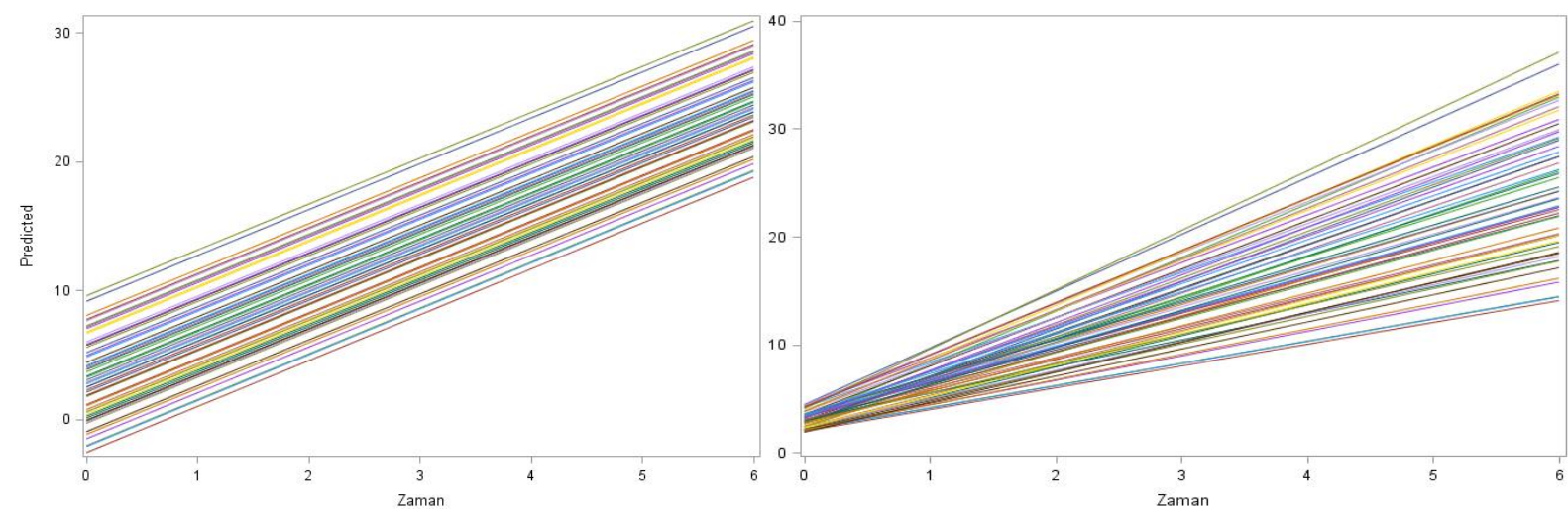

Şekil 3.Dişi oğlaklar için kesim noktasının (sol) ve hem kesim noktasının hem de eğimin şansa bağlı olduğu (sağ) iki düzeyli modeller ile elde edilen bireysel büyüme eğrisi

Gökdal ve ark.’nın (2013) 146 baş SK, AK ve K keçisi kullanarak yaptıkları çalışmada yedinci ay canlı ağırlığı dışında genotipler arası farklılık, üçüncü ay dışında da ana yaşları arasındaki farklılık anlamlı bulunmamıştır. Bu sonuçlar, hem dişi hem erkek için ayrı ayrı elde edilen şimdiki çalışmanın sonuçları ile benzer olmuştur. Ancak, Gökdal ve ark. (2013) ve Atay ve ark. (2010) tarafindan yapılan çalışmalarda, oğlakların büyüme-gelişme performansı üzerine işletmeler arası farklılığın anlamlı olması bu çalışmadan elde edilen sonuçlardan farklılık göstermiştir. Zira bu çalışmada hem erkek hem dişi oğlakların büyüme performansı üzerine işletme ve doğum tipinin tek başına herhangi bir açıklayıcı önemli etkisi bulunmamıştır (Tablo 4 Model III).

\section{SONUÇ}

Çok düzeyli modellerin sahip olduğu avantajlar bu modellerin tekrarlamalı veri analizlilerinde kullanım sıklığını artırmıştır. Bu avantajlar, eksik gözlemlerin varlığından etkilenmemesi, çeşitli kovaryans yapılarının denenerek veriye en uygun kovaryans yapısının seçilebilmesine izin vermesi, zamanla değişen ve değişmeyen açıklayıcı değişkenlerin modelde yer almasına imkan tanıması, daha fazla hiyerarşik yapı veya sınıflandırmanın kolaylıkla modellenebilmesi ve sürü için ortalama büyüme performansını belirlemesinin yanı sıra bireysel büyüme performanslarının belirlenebilmesi şeklinde özetlenebilir.

Hayvancılıkta ekonomik öneme sahip olan büyüme ve gelişme performansının belirlenmesi için yapılan çalışmalarda veriler, tekrarlamalı olarak elde edilmektedir. Bu çalışmada, çok düzeyli modelleme analiz tekniği kullanılarak erkek ve dişi SK, AK ve K oğlaklarının ortalama ve bireysel büyüme performansları belirlenmiştir. Buna göre oğlakların büyüme ve gelişme özelliklerine ilişkin tutulan kayıtların etkin olarak değerlendirilebilmesi amacıyla ele alınan modellerden UN kovaryans yapısının kullanıldığı Model III, diğer modellere göre dişi ve erkek oğlakların büyüme ve gelişme performanslarındaki değişimi en iyi açıklayan model olmuştur.

\section{KAYNAKLAR}

Aitkin, M., \& Longford, N. (1986). Statistical modelling issues in school effectiveness studies. Journal of the Royal Statistical Society: Series A (General), 149(1), 1-26.

Akaike, H. (1974). A new look at the statistical model identification. IEEE Transaction on Automatic Control, 19(6), 716-724.

Akkol, S., Karakuş, F., \& Cengiz, F. (2018). Multilevel Analysis for Repeated Measures Data in Lambs .Journal of Agricultural Sciences, 24(2), 218-226. 
Atay, O., Gökdal, Ö., \& Eren, V. (2010). Reproductive characteristics and kid marketing weights of Hair goat flocks in rural conditions in Turkey. Cuban Journal of Agricultural Sciences, 44(4), 353-358.

Atay, O., Gökdal, Ö., Kayaard1, S., \& Eren, V. (2011). Fattening performance, carcass characteristics and meat quality traits in Hair goat (Anatolian Black) male kids. Journal of Animal and Veterinary Advances, 10(10), 1350-1354.

Browne, W. J., \& Draper, D. (2006). A comparison of Bayesian and likelihood-based methods for fitting multilevel models. Bayesian analysis, 1(3), 473-514.

Bryk, A. S., \& Raudenbush, S. W. (1986). A hierarchical model for studying school effects. Sociology of Education. 59, 1-17.

Çelik, H.T., \& Olfaz, M. (2018). Reproductive performance of Hair goat and growth traits of Hair Goat and Saanen x Hair (F1) crossbred kids in rural conditions. Bulgarian Journal of Agricultural Science, 24(2) 296-302.

Erduran, H., \& Dag, B. (2016). Body Weight and Body Measurement Traits of Hair, Alpine x Hair F1 and Saanen x Hair F1 Crossbred Does Raised at Rural Conditions in Konya Province. Selcuk J Agr Food Sci, 30(1):49-53.

Ghaderi_Jzefrehei, M. O. S. T. A. F. A., Rafeie, F., Behzadi, M. R. B., Nazari, S., Dolatabadi, M., Samadian, F., ... \& Najafabadi, H. A. (2018). Simple hierarchical and general nonlinear growth modeling in sheep. Turkish Journal of Veterinary and Animal Sciences, 42(4), 326-334.

Gökdal, Ö., \& Atay, O. (2010). Kavşit Köyü ve Yöresi Keçicilik Projesi: Gelişmeler. Ulusal Keçicilik Kongresi 2010, Çanakkale Onsekiz Mart Üniversitesi, 24-26 Haziran 2010. Poster, Bildiriler Kitabı: 150-153.

Gökdal, Ö., \& Atay, O. (2011). Türkiye'de Kıl Keçisi Yetiştiriciliği ve Kıl Keçisinin Et Üretimi. Tarım Türk Dergisi, Eylül-Ekim 2011, 31, 6, 162-166.

Gökdal, Ö., Atay, O., Özuğur, A. K., \& Eren, V. (2013). Yetiştirici koşullarında K1l, Saanen x Kıl ve Alpin x Kıl melezi oğlaklarda büyüme-gelişme ve yaşama gücü özellikleri. Hayvansal Üretim, 54(1), 30-37.

Goldstein, H. (1989). Restricted unbiased iterative generalized least-squares estimation. Biometrika, 76(3), 622-623.

Goldstein, H. (2003). Multilevel Statistical Models, 3rd edn. London: Arnold.

Goldstein, H., Browne, W., \& Rasbash, J. (2002). Multilevel modelling of medical data. Statistics in medicine, 21(21), 3291-3315.

Hedeker, D., \& Gibbons, R. D. (2006). Longitudinal data analysis. New York: Wiley. ISBN: 978-0-471-420279

Hedeker, D. (2004). An Introduction to Growth Modelling. In: D Kaplan (Ed), The Sage Handbook of Quantitative ethodology for the Social Sciences. Sage Publications, Thousand Oaks, CA

Hox, J. J.(2010). Multilevel Analysis: Techniques and Applications. Mahwah, NJ: Erlbaum.

Kwok, O. M., Underhill, A. T., Berry, J. W., Luo, W., Elliott, T. R., \& Yoon, M. (2008). Analyzing longitudinal data with multilevel models: An example with individuals living with lower extremity intra-articular fractures. Rehabilitation psychology, 53(3), 370.

Leeuw, J., \& Kreft, I. G. G. (1986). Random coefficient models for multilevel analysis. Journal of Educational Statistics, 11, 55-85. 
Raudenbush, S. W., \& Bryk, A. S. (2002). Hierarchical linear models: Applications and data analysis methods, 2nd ed. Newbury Park, CA: Sage.

SAS (2014) SAS/STAT, SAS Institute Incorporation, Cary, NC, USA

Schwarz G. (1978). Estimating the dimensions of a model. Annals of Statistics, 6, 461-464.

Şengonca, M., Taskin, T., \& Kosum, N. (2003). Saanen x Kil Keçi Melezlerinin ve Saf Kil Keçilerinin Kimi Verim Özelliklerinin Belirlenmesi Üzerine Eş Zamanli Bir Araştirma. Turkish Journal of Veterinary \& Animal Sciences, 27(6), 1319-1325.

Shek, D. T. L., \& Ma, C. M. S. (2011). Longitudinal data analyses using linear mixed models in SPSS: Concepts, Procedures and Illustrations. The Scientific World Journal, 11, 42-76.

Şimşek, Ü. G., Bayraktar, M., \& Gürses, M. (2007). Saanen x K1l Keçisi F1 ve G1 melezlerinde büyüme ve yaşama gücü özelliklerinin araştırılması. Fırat Üniversites Sağlık Bilimleri Dergisi, 21(1), 21-26.

Singer J. D. (1998). Using SAS PROC MIXED to fit multilevel models, hierarchical models, and individual growth models. Journal of Educational and Behavioral Statistics, 24, 323-355.

Snijders, T. A. B., \& Bosker, R. J. (1999). Multilevel analysis: An introduction to basic and advanced multilevel modeling. CA: Sage Publications.

TUIKK (2017). Türkiye İstatistik Kurumu. http://www.tuik.gov.tr/PreTablo.do?alt_id=1002. Erişim 26 Şubat 2019.

Wang, Z., \& Goonewardene, L.A. (2004). The use of MIXED models in the analysis of animal experiments with repeated measures 